\title{
Перемешивание испаряющихся капель на жидких подложках, вызванное фестонной неустойчивостью
}

\author{
() О.А. Тарасов, Н.А. Тарасова І, Н.А. Иванова
}

Тюменский государственный университет

๑E-mail: nata555li@mail.ru

Поступило в Редакцию 16 июня 2016 г.

Предложена новая конфигурация микрофлюидного смесителя, в котором перемешиваемый объем в виде капли летучей жидкости лежит на слое воды. Перемешивание происходит за счет инжекции фестонов, возникающих в капле под действием испарительной термокапиллярной конвекции, из периферии капли в ее центр. Установлена линейная связь между скоростью инжекции и температурой слоя и показано, что за время жизни капли она успевает перемешаться несколько раз.

DOI: 10.21883/PJTF.2017.17.44946.16367

Перемешивание объемов микрокапель является одной из практических задач микрофлюидики. Обычно она решается приложением к капле электрических [1], магнитных [2] или тепловых [3] полей и предполагает наличие сложной системы каналов или по крайней мере твердой подложки [3-5]. Однако не все образцы (особенно биологические) позволяют подобное воздействие, а существующие схемы перемешивания увеличивают стоимость микрофлюидных устройств. Задачей настоящей работы является разработка микрофлюидного смесителя, не имеющего указанных недостатков. Для этого предложено заменить базу устройства: перейти от твердой подложки к жидкой, а для перемешивания использовать явление фестонной нестабильности капли летучей жидкости, лежащей на слое нерастворимой в ней другой жидкости (жидкой подложке) [6]. Перемешивание достигается за счет инжекции фестонов с периферии капли в ее центр.

Для оценки эффективности устройства определялось время перемешивания вещества в капле путем измерения диаметра фестонов и скорости их инжекции относительно края капли в зависимости от 


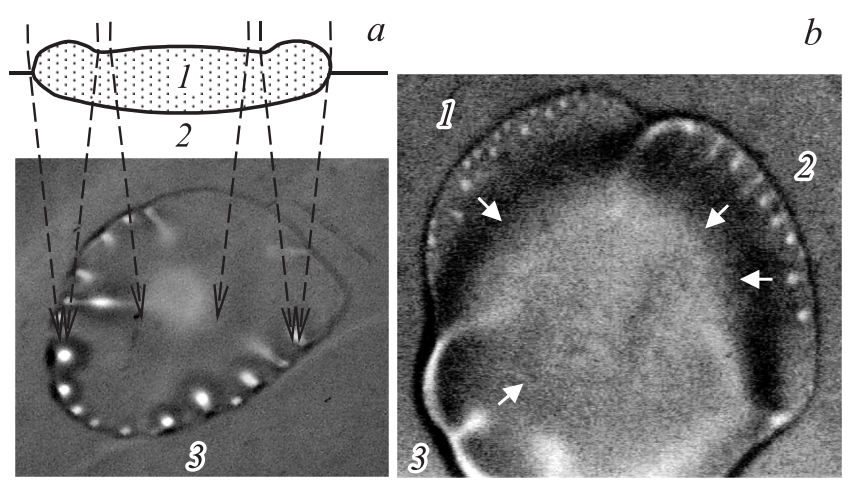

Рис. 1. $а$ - теневая картина (3) капли o-ксилола (1) с фестонами и центральным холмиком на слое воды (2) с температурой $45^{\circ} \mathrm{C}$, размер кадра $25 \times 21 \mathrm{~mm}$. $b-$ капля изооктана на слое воды с температурой $36^{\circ} \mathrm{C}$, размер кадра $16 \times 14 \mathrm{~mm} .1-3-$ номера областей.

температуры подложки. Подложкой служила дистиллированная вода с температурой от 24 до $45^{\circ} \mathrm{C}$, а веществами капли - химически чистые изооктан, $н$-гептан и $o$-ксилол (рис. $1, a)$. Капля объемом $50 \mu 1$ помещалась на подложку толщиной $4 \mathrm{~cm}$, изображение капли с фестонами визуализировалось прямым теневым методом на дне сосуда и осуществлялись его видеозапись и покадровая обработка. Начальный диаметр капель был 10-20 mm, что соответствует их толщине $175-700 \mu \mathrm{m}$, а фокусное расстояние фестонов - около $4 \mathrm{~cm}$, что соответствует их радиусу кривизны $2 \mathrm{~cm}$ и приращению толщины капли над ними в $6 \mu \mathrm{m}$.

Интересная особенность явления, затрудняющая его исследование, состоит в том, что пространственные флуктуации скорости испарения вещества капли приводят к ее неравномерному охлаждению и формированию термокапиллярных (ТК) течений, искажающих круглый профиль капли. В свою очередь искажение профиля капли приводит к пространственной неоднородности скорости испарения. Таким образом, имеется обратная связь между скоростью испарения и локальной горизонтальной кривизной профиля капли.

Так, если возникает выпуклый выступ границы капли относительно ее неискаженной круговой границы, это вызывает усиление испарения

4 Письма в ЖТФ, 2017, том 43, вып. 17 
вещества выступа, формирование ТК-течений в выступ и его рост. В ряде случаев, поскольку минимизации поверхностной энергии соответствует сферическая форма выступа, происходит втягивание вещества в область центра выступа, утоньшение перешейка, соединяющего выступ с каплей, разрыв перешейка и отрыв вещества выступа от объема материнской (основной) капли в виде микрокапли. Микрокапля движется под действием ТК-течений в ней, направленных в сторону от материнской капли, т.е. в сторону с большей скоростью испарения. В большинстве случаев микрокапля не успевает формироваться и отрываться от материнской капли, а происходит испарение тонкой пленки жидкости на периферии выступа, уменьшение кривизны выступа и втягивание выступа в материнскую каплю под действием капиллярных статических сил. При формировании вогнутого профиля границы капли все происходит с точностью до наоборот. Чаще же формируются незначительные (5-10\% от радиуса капли) искривления профиля капли, которые не успевают усиливаться, а за $0.5-1$ s релаксируют (рис. $1, a)$.

На границе капли вблизи области формирования фестона также происходит искажение профиля капли (рис. 1, $b$, область 3), которое эволюционирует как по мере роста фестона, так и в процессе его инжекции, поскольку рост фестона обусловлен притоком вещества к краю капли, а его инжекция - уносом вещества капли с ее периферии в центр и одновременным притоком вещества с прилегающих границ капли к месту, откуда фестон инжектировал, и вслед ему. В конечном итоге пространственное различие начальных условий на краю капли приводит к различию условий для роста и инжекции фестонов. Так, на рис. $1, b$ три области с различной толщиной края капли (толщина растет в ряду $1 \rightarrow 3$ ) дают фестоны трех различных размеров.

Важно также отметить, что, поскольку капля лежит не на твердой, а на жидкой подложке, отсутствует условие прилипания и течение в капле индуцирует течение в объеме подложки. По этой причине хаотические течения в капле (и соответственно в подложке) не только искажают профиль капли, но и приводят к ее горизонтальному движению (кривая 3 на рис. 2,a). При этом становятся различными и скорости испарения на разных краях капли, так как наступающий фронт капли оказывается в области с меньшей концентрацией паров ее вещества, а отступающий фронт - с большей.

Учитывая движение капли по подложке и изменение ее профиля в процессе инжекции фестонов, на каждом кадре (размером $600 \times 800$ рх

Письма в ЖТФ, 2017, том 43, вып. 17 


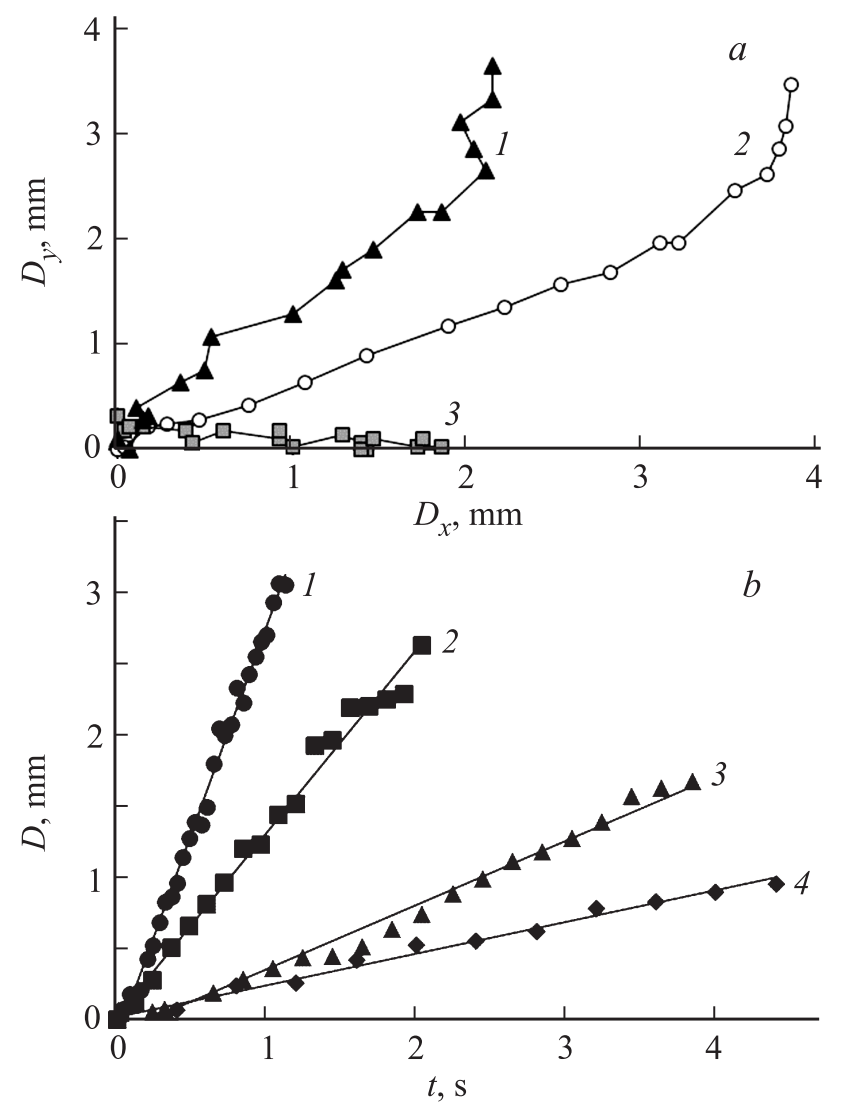

Pис. 2. $a$ - типичные смещения $D_{x}$ и $D_{y}$ по двум осям края капли (3) и центра фестона (2) относительно сосуда, а также смещение фестона относительно края капли $(1)$ с шагом $0.08 \mathrm{~s}$. Капля изооктана на слое воды с температурой $45^{\circ} \mathrm{C}$. $b$ - смещение $D$ фестонов в зависимости от времени $t$ с начала инжекции относительно края капли изооктана при различных температурах водной подложки. $T,{ }^{\circ} \mathrm{C}: 1-45,2-37,3-32,4-24$.

при масштабе $28 \mathrm{px} / \mathrm{mm}$ ) измеряли координаты центра фестона и координаты ближайшего к нему края капли (кривые 2 и 3 на рис. 2,a). При покадровой обработке видеозаписи инжекции выбирались фестоны,

4* Письма в ЖТФ, 2017, том 43, вып. 17 

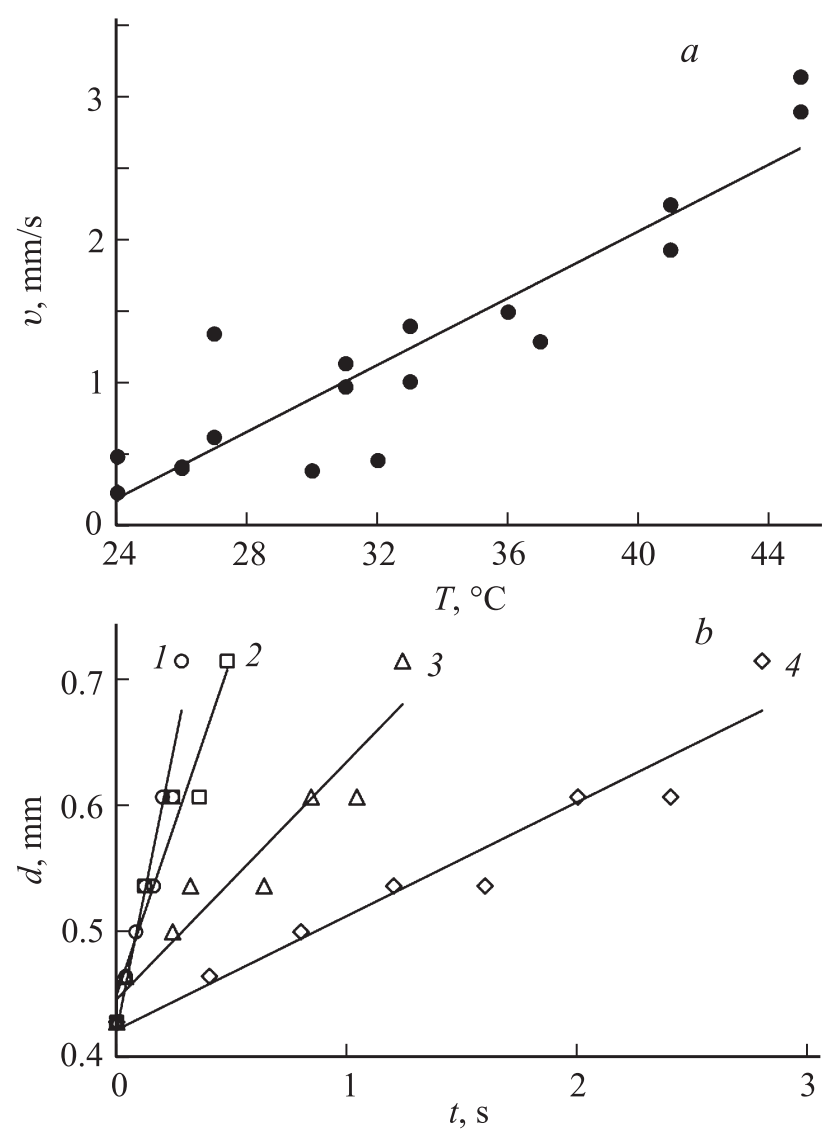

Рис. 3. $a-$ скорости $v$ фестонов в капле изооктана на водной подложке в зависимости от ее температуры $T$. $b$ - диаметры $d$ фестонов в той же системе в зависимости от времени $t$ с момента начала их инжекции при различных температурах подложки. $T,{ }^{\circ} \mathrm{C}: 1-45,2-37,3-32,4-24$.

для которых отсутствовало существенное изменение профиля ближайшей границы капли и неравномерное движение капли по подложке. Смещение фестона определялось как смещение относительно края капли за время между кадрами $(1 / 25 \mathrm{~s})$ (кривые 1 на рис. $2, a$ и $b)$. Такая 
оценка смещения фестона точнее, чем оценка относительно центра масс капли, так как под действием хаотических изменений профиля капли положение ее центра также хаотически меняется, и все флуктуации ее границ (а не только границ вблизи фестона) вносят погрешность в определение скорости фестона.

Обнаружена сильная линейная корреляция (коэффициент 0.85) скорости фестонов и температуры подложки (рис. 3,a), но прямой зависимости между данными параметрами нет. Это связано с тем, что из-за искажения профиля капли и движения капли относительно облака ее паров условия роста и инжекции для каждого фестона индивидуальны. Эти условия различны также и потому, что расстояние между соседними фестонами неодинаково (рис. 1, $a$ ) и определяется процессами инжекции близлежащих фестонов (тем, как близко они расположены, в какой момент и в какую сторону инжектируют).

Кроме того, под действием испарительной ТК-конвекции в центральных областях капли формируются холмики, близость которых также влияет на рост и инжекцию фестонов (рис. $1, a$ ). Стремясь уменьшить поверхностную энергию, фестоны инжектируют не в центр капли, а в центр ближайшего холмика или в след недавно инжектировавшего фестона. При этом наличие холмика или указанного следа вызывает более раннюю инжекцию ближайшего фестона, как и наличие выпуклости капли в виде следа от инжектировавшего фестона. Поэтому при заданной температуре подложки скорости инжекции фестонов различаются, причем это наблюдается для фестонов, инжектирующих как последовательно, так и одновременно (рис. $1, b$ ). Различие в скорости инжекции фестонов такое, как будто они инжектируют при температуре на $1-7^{\circ} \mathrm{C}$ выше или ниже заданной (рис. $3, a$ ).

На рис. 2, $b$ показана зависимость смещения фестонов с момента их инжекции относительно края капли для различных температур жидкой подложки, а на рис. $3, b-$ изменение диаметров фестонов в процессе их инжекции (начало инжекции принято за $0 \mathrm{~s}$ ). Зависимости диаметров фестонов построены для меньшего интервала времени, чем зависимости смещения фестонов, так как при диаметре фестонов свыше $0.7 \mathrm{~mm}$ их границы из-за размытия было невозможно определить, в то время как положение центра фестона еще уверенно определялось.

Из рис. $2, b$ и $3, b$ хорошо видно, что как смещения фестонов, так и их диаметры зависят от времени линейно. При этом, как указывалось выше, для заданного вещества капли скорость фестонов растет с

Письма в ЖТФ, 2017, том 43, вып. 17 
Скорости инжекции фестонов, времена жизни капель и времена их перемешивания фестонами в зависимости от вещества капли и температуры подложки

\begin{tabular}{c|c|c|c|c|c|c}
\hline $\begin{array}{c}\text { Жидкость } \\
\text { капли }\end{array}$ & $\begin{array}{c}\text { Температура } \\
\text { водной } \\
\text { подложки, }\end{array}$ & $\begin{array}{c}\text { Вязкость } \mathrm{C} \\
\text { жидкости, } \\
10^{3} \mathrm{~Pa} \cdot \mathrm{s}[7]\end{array}$ & $\begin{array}{c}\text { Скорость } \\
\text { инжекции } \\
\text { कестонов, } \\
\mathrm{mm} / \mathrm{s}\end{array}$ & $\begin{array}{c}\text { Время } \\
\text { жизни } \\
\text { капли } t_{l}, \mathrm{~s}\end{array}$ & $\begin{array}{c}\text { Время полного } \\
\text { пемешивания } \\
\text { капли фесто- } \\
\text { нами } t_{m}, \mathrm{~s}\end{array}$ & $t_{l} / t_{m}$ \\
\hline Изооктан & 45 & 0.38 & $2.64^{*}$ & 60 & 30 & 2.0 \\
$\gg$ & 37 & 0.42 & $1.71^{*}$ & 80 & 45 & 1.8 \\
$\gg$ & 32 & 0.44 & $1.12^{*}$ & 100 & 80 & 1.3 \\
$\gg$ & 24 & 0.485 & $0.19^{*}$ & 120 & 405 & 0.3 \\
$o$-ксилол & 45 & 0.59 & 0.69 & 180 & 45 & 4.0 \\
н-гептан & 37 & 0.35 & 2.54 & 45 & 12 & 3.8
\end{tabular}

* Значения для изооктана рассчитаны на основе линейного тренда на рис. 3, a

ростом температуры. При заданной же температуре скорость фестонов выше у менее вязких жидкостей. Однако обратно пропорциональной зависимости скорости инжекции от динамической вязкости капли не наблюдается, что указывает на сильно нелинейный характер явления. Так, рост температуры изооктана от 24 до $45^{\circ} \mathrm{C}$ вызывает уменьшение его вязкости в 1.3 раза [7], в то время как скорость инжекции фестонов растет в 14 раз (см. таблицу). Аналогичный нелинейный результат получается при сопоставлении скоростей инжекции в каплях разных жидкостей при одинаковых температурах слоя воды. Так, при температуре $45^{\circ} \mathrm{C}$ вязкость o-ксилола в 1.6 раза больше вязкости изооктана [7], а скорость инжекции в капле $о$-ксилола в 3.8 раза меньше, чем в капле изооктана.

В таблице приведено определенное в эксперименте время жизни капель разного состава (с момента их помещения на подложку до полного испарения) при разной температуре подложек, а также даны оценки времени полного перемешивания капель на основе экспериментальных данных об объемах и скоростях инжекции фестонов. При температуре подложки выше $30^{\circ} \mathrm{C}$ в течение жизни объем капли успевает перемешаться 1-4 раза (см. таблицу). Поскольку процесс фестонного перемешивания происходит без приложения внешних полей и использования сложных микроканалов, это существенно упрощает и 
удешевляет микрофлюидные смесители [8]. Таким образом, на примере процесса перемешивания показано, что замена твердой базы микрофлюидики на жидкую дает ряд преимуществ и открывает новые перспективы для микрофлюидики.

Работа выполнена при финансовой поддержке Российского фонда фундаментальных исследований (проект № 14-01-92602 КО_а) и Министерства образования и науки РФ (проект № 1019).

\section{Список литературы}

[1] Тимиров Ю.И., Скалдин О.А., Басырова Е.Р. // Письма в ЖТФ. 2015. Т. 41. B. 7. C. $62-65$.

[2] Диканский Ю.И., Борисенко О.В., Беджсанян М.А., Коробов М.И. // Письма в ЖТФ. 2015. Т. 41. B. 9. C. 24-30.

[3] Grigoriev R.O., Schatza M.F., Sharmab V. // Lab Chip. 2006. V. 6. P. 1369-1372.

[4] Nguyen N.-T., Wu Z. // J. Micromech. Microeng. 2005. V. 15. P. 1-16.

[5] Whitesides G.M., Stroock A.D. // Phys. Today. 2001. V. 54. P. 42-48.

[6] Тарасов О.А., Горбачева Н.А. // Письма в ЖТФ. 2007. Т. 33. В. 4. С. 39-44.

[7] Vargaftik N.B. Handbook on thermophysical properties of gases and liquids. Ed. 2. M.: Nauka, 1972. 720 p.

[8] Shabarov A.B., Tarasova N.A., Tarasov O.A. Method of creating flow in liquid droplet. RF Patent N 2403554, 2010.

Письма в ЖТФ, 2017, том 43, вып. 17 